\title{
Physician burnout a major concern
}

\author{
Cite as: CMAJ 2017 October 2;189:E1236-7. doi: 10.1503/cmaj.1095496
}

Posted on cmajnews.com on Sept. 8, 2017.

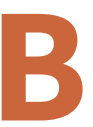

urnout is a major problem in the medical profession and work overload is the primary driver.

"This, of all the factors, is the strongest predictor of burnout," Dr. Sandra Roman, a family advisor for the Quebec Physicians' Health Program, said at the Canadian Conference on Physician Health in Ottawa.

Many physicians also feel they have little control over their workloads and this combination - high demand and low control - is the "perfect storm for burnout," according to Roman. Other contributing factors to burnout include insufficient recognition for many extra hours of work, conflicting values in the practise of medicine, and a breakdown of community within the profession.

Roman cited a 2012 study that found $45.8 \%$ of physicians in the United States had reported at least one symptom of burnout. The highest rates of burnout were found among front-line clinicians, such as family doctors and emergency physicians. According to the study, doctors are at higher risk of burnout than the general population and are more likely to be dissatisfied with their work-life balance.

"Although the practice of medicine can be incredibly meaningful and personally fulfilling, it is also demanding and stressful," the study authors noted. "Burnout also seems to have adverse personal consequences for physicians, including contributions to broken relationships, problematic alcohol use, and suicidal ideation."

There is much concern about this problem in the medical profession because the costs are so high. Burnout can have a negative effect on the physical and mental health of physicians. It can also lead to decreases in productivity, cutbacks in work hours or early retirement from the profession.

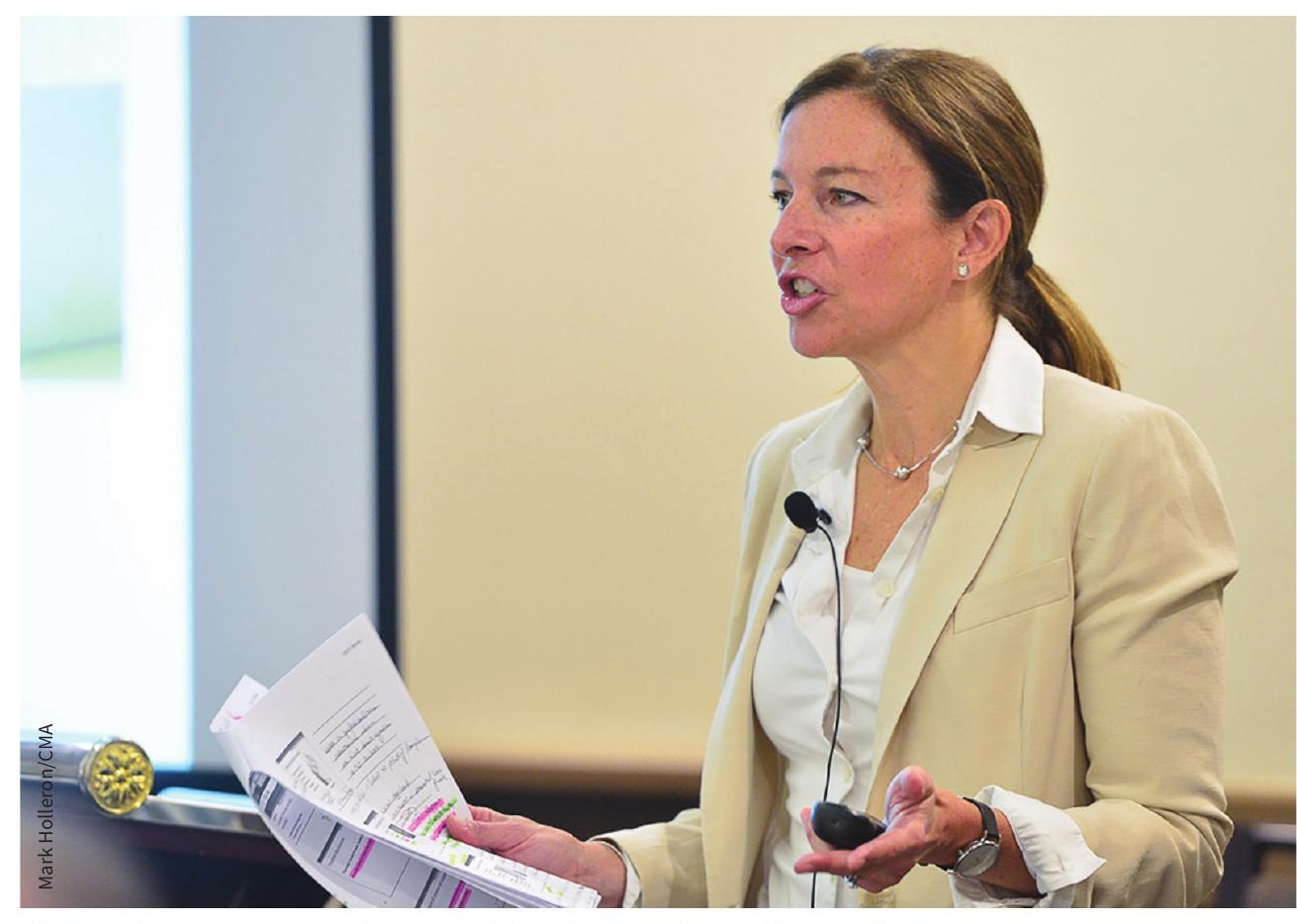

Physician burnout is common but reversible and preventable, said Dr. Sandra Roman.

"Physician burnout has been shown to predict medical error more strongly than fatigue," Dr. Tait Shanafelt, recently appointed as Stanford Medicine's first chief wellness officer, said in the first plenary address of the conference.

Doctors who keep working despite experiencing signs of burnout are likely to provide lower-quality and less safe care than earlier in their careers. Burnout has been shown to affect prescribing habits, test ordering and medical professionalism. The cost of physician burnout in the US is over $\$ 200$ million per year, according to Shanafelt.

Though common and well-studied, burnout is not an official medical diagnosis. It is not recognized by the Diagnostic and Statistical Manual of Mental Disorders. "It is not something we are used to working with as clinicians," said Roman.
Shanafelt cautioned against making the common mistake of confusing depression and burnout. "Depression is a well-understood, treatable mental illness that affects all aspects of life," said Shanafelt. "Burnout is a condition that affects work performance and has some spillover into the rest of a person's life."

Self-awareness is important for physicians in recognizing the symptoms of burnout. These symptoms include emotional exhaustion, a loss of empathy, cynicism, a feeling of detachment from patients, and a low sense of personal accomplishment. One tool physicians can use if they suspect they are experiencing these or other signs of burnout is the Maslach Burnout Inventory, a self-administered questionnaire.

The good news, according to both Roman and Shanafelt, is that there are 
multiple strategies to address physician burnout.

"Burnout is something that is, luckily, reversible, even preventable," said Roman. Leaders of medical teams play an important role in reducing the burnout rates of those under their leadership, noted Roman. It is important that leaders show they are open to feedback, respect the opinions of less-experienced colleagues, and empower team members to do their work and advance in their careers.

At the organizational level, the gold standard for addressing this problem, according to Roman, is the Mayo Clinic's "Nine Organizational Strategies to Promote Engagement and Reduce Burnout." These strategies include acknowledging the problem, developing targeted interventions, cultivating community at work, and providing resources to promote resilience and self-care.

At the individual level, physicians must remember to take care of themselves to exercise, eat well, get enough sleep, and invest in personal relationships. Doctors must also recognize their own vulnerability to burnout. Otherwise they may slip into depending on risky coping mechanisms.

"For certain people, that could be over-work," said Roman. "For certain people, that could be an extra drink during the week."

Doctors can access online resources to learn how to enhance resiliency, manage fatigue and reduce stress. They can also participate in group interventions, mindfulness training and facilitated discussion groups.

Roger Collier, CMAJ 